\title{
Level of agreement between Nexfin and thermodilution cardiac output in morbidly obese patients undergoing laparoscopic surgery
}

\author{
P. Schraverus' ${ }^{1}$, M. Kuijper ${ }^{1}$, C. Boer ${ }^{1}$, C. Boly ${ }^{1}$, S. van Kralingen ${ }^{2}$ \\ Departments of Anesthesiology ${ }^{1}$, VU University Medical Center, Amsterdam, \\ Departments of Anesthesiology² , Onze Lieve Vrouwe Gasthuis West, Amsterdam, The Netherlands
}

\section{Introduction}

Morbidly obese patients are at increased risk for intraoperative hemodynamic instability, which requires intensive monitoring. The non-invasive Nexfin ${ }^{\circledR}$ monitor is used to monitor cardiac output (CO), it is however unknown whether its weight-based algorithm also applies to patients with extreme bodyweight. Here we investigated agreement and trending ability of Nexfin CO measurements compared to thermodilution $\mathrm{CO}$ measurements of the PiCCO in morbidly obese patients.

\begin{tabular}{|c|c|c|}
\hline \multirow{3}{*}{$\begin{array}{l}\text { We used the Nexfin and PiCCO thermodilution methods to measure } \\
\text { CO in morbidly obese patients how underwent laparoscopic bariatric } \\
\text { surgery on } 12 \text { consecutive pre determined time points. }\end{array}$} & Time point & Description \\
\hline & 1 & After induction of anaesthesia \\
\hline & 2 & After positioning, before pneumoperitoneum \\
\hline & 3 & After pneumoperitoneum \\
\hline & $4,5,6,7$ & $15,30,45$ and 60 minutes following pneumoperitoneum \\
\hline & 8 & Just before release of pneumoperitoneum \\
\hline & 9 & Immediately after release of pneumoperitoneum \\
\hline & 10 & Immediately after extubation \\
\hline & 11,12 & 30 and 60 minutes following extubation \\
\hline
\end{tabular}

Results

\section{Patient characteristics}

Patient characteristic $\mathbf{N}$

Age (years)

Females (\%)

Body length (m)

Body weight (kg)

Body mass index (kg. $\left.\mathrm{m}^{-2}\right)$

ASA classification

Level of agreement - Bland Altman analysis

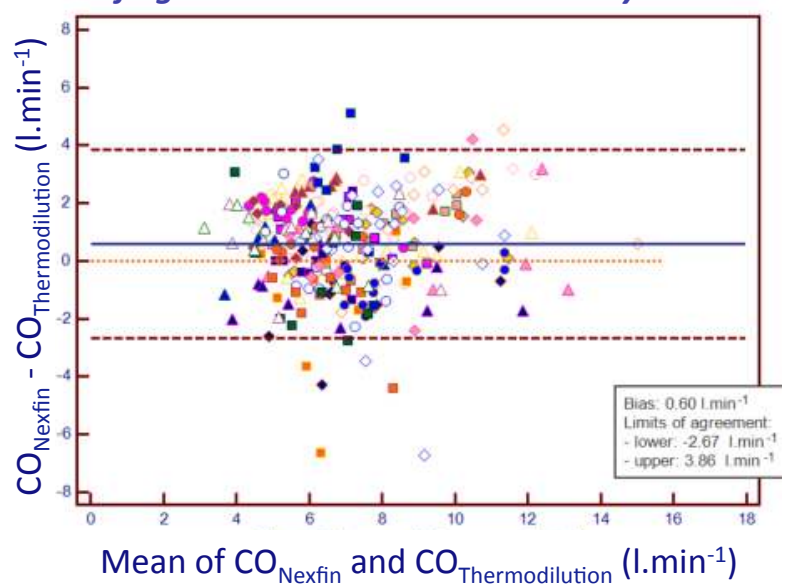

Bland Altman analysis corrected for multiple measurements revealed a bias of 0.60 (1.62) I. $\mathrm{min}^{-1}$ with limits of agreement from -2.67 to 3.86 I. $\mathrm{min}^{-1}$. The precision error was $46 \%$.
Haemodynamic parameters during surgery
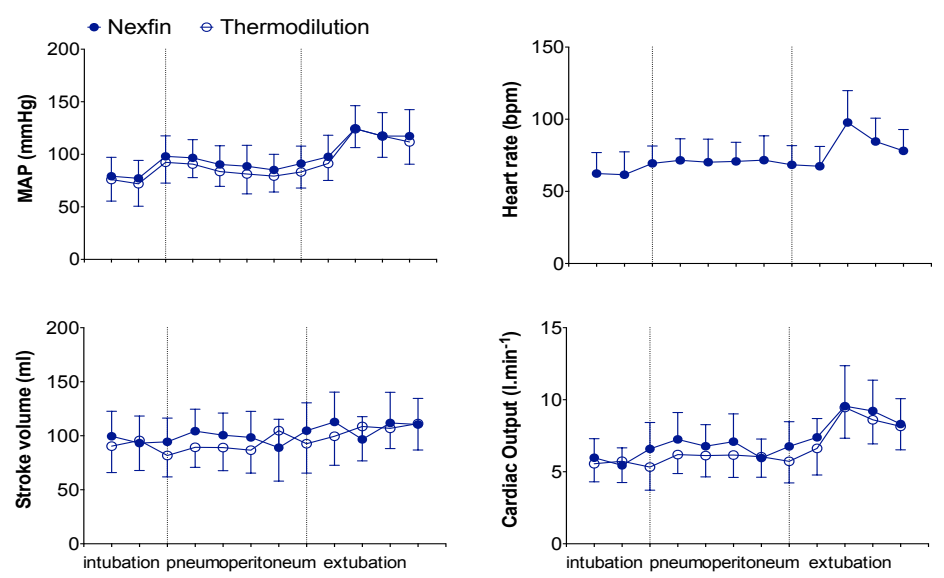

Course of the mean arterial pressure (MAP), heart rate (HR), stroke volume (SV) and cardiac output (CO) as measured by the Nexfin (blue circles) and thermodilution (white circles) during bariatric surgery.

\section{Trending ability}

Trending of cardiac output by the Nexfin device was insufficient when compared to thermodilution as shown by a four-quadrant and Polar plot analysis. The angular concordance rate was $77 \%$. Polar plot analysis resulted in an angular bias of $2.61^{\circ}$, radial limits of agreement of $-60.08^{\circ}$ to 49.82.

\section{Conclusion}

We found an unacceptable level of agreement and trending of cardiac output by the Nexfin compared to thermodilution in morbidly obese patients undergoing laparoscopic surgery according the Critchley criteria. Our data suggest that the Nexfin monitor should therefore not be used in patients with excessive body weight. 